\title{
Potential of the polychaete Hediste diversicolor fed on aquaculture and biogas side streams as an aquaculture food source
}

\author{
Haiqing Wang ${ }^{1,2, *}$, Andreas Hagemann ${ }^{2}$, Kjell Inge Reitan ${ }^{1}$, Jørgen Ejlertsson ${ }^{3}$, \\ Håvard Wollan ${ }^{4}$, Aleksander Handå ${ }^{2}$, Arne M. Malzahn ${ }^{2}$
}

\author{
${ }^{1}$ Norwegian University of Science and Technology, Department of Biology, 7491 Trondheim, Norway \\ ${ }^{2}$ SINTEF Ocean, 7465 Trondheim, Norway \\ ${ }^{3}$ Scandinavian Biogas, 58273 Linköping, Sweden \\ ${ }^{4}$ Biokraft AS, 7042 Trondheim, Norway
}

\begin{abstract}
We evaluated the potential of the marine bristleworm Hediste diversicolor (Polychaeta) to recycle side streams from aquaculture and biogas production. Polychaetes were fed along a gradient from pure aquaculture sludge (SS) to pure solid biogas digestate (SBD) in $33 \%$ steps, with a positive control reared on fish feed (FF). Worms fed with FF showed the highest specific growth rate; there were no significant differences in growth rates among worms fed pure SS, pure SBD or their mixtures. While the diets differed significantly in protein concentrations, the worms showed comparable protein concentrations at the end of the $30 \mathrm{~d}$ rearing period $(42-47 \%$ of dry weight). Lipid content in the worms was positively correlated with that in their diets. The worms on mixtures of SS and SBD with different ratios showed similar amino acid profiles. Fatty acid (FA) composition in the polychaetes reflected diet, where increased fractions of SBD resulted in an increase in long-chain polyunsaturated FAs, such as arachidonic (C20:4 n-6) and eicosapentaenoic (C20:5 n-3) acids, whereas increased ratios of SS increased docosapentaenoic (C22:5n-3) and docosahexaenoic (C22:6 n-3) acids. These results suggest that polychaetes can recycle organic nutrients from aquaculture and biogas side streams into high-quality proteins and lipids, and can potentially serve as ingredients for aquafeeds.
\end{abstract}

KEY WORDS: Recycling $\cdot$ Salmon culture $\cdot$ Aquaculture waste $\cdot$ Solid biogas digestate $\cdot$ Aquafeed

\section{INTRODUCTION}

The European Resource Efficiency Platform manifesto (EC 2014, p. 4) states: 'In a world with growing pressures on resources and the environment, the EU has no choice but to go for the transition to a resource-efficient and ultimately regenerative circular economy'. The manifesto is widely cited and sums up the need to develop high-quality recycling programs and move away from landfill approaches to waste disposal. Bioindustries are especially wellsuited to spearhead circular principles, as biological processes inherently rely on recycling and reuse of

*Corresponding author: haiqing.wang@ntnu.no organic and inorganic compounds. Many processes that are potentially useful components of a circular economy are already realized in nature and simply need adaptation to industrial scales and requirements (Van Huis et al. 2013, Kadowaki \& Kitadai 2017, Brennan 2018).

Finfish aquaculture is constantly growing, and salmon aquaculture in particular has increased strongly the last several decades (Clarke 2017). The growth in salmon aquaculture has been followed by an increased interest in the use of recirculating aquaculture systems (RAS), which aim to integrate aquaculture into a circular economy approach (Dalsgaard et

() The authors 2019. Open Access under Creative Commons by Attribution Licence. Use, distribution and reproduction are unrestricted. Authors and original publication must be credited. 
al. 2013). Currently, the majority of salmon farming takes place in open sea cages, where recapturing waste is either not possible or not implemented; hence, large amounts of nutrients are lost to the external environment (Hamilton et al. 2016). The production of salmon smolt, however, takes place in land-based farms, where it is traditionally cultured with the use of flow-through systems. Recently, however, smolt producers have increasingly been converting their flow-through systems to RAS as less energy is required for heating intake water, year-round temperature control is possible, limited freshwater access is less problematic, bio-security and water quality are easier to maintain, and growth is generally better (Bergheim et al. 2009, Summerfelt et al. 2015, 2016). With the inherent need for particle treatment in RAS, where more than $98 \%$ of the particulate matter (Del Campo et al. 2010) can be captured and discarded as sludge (Gorle et al. 2018), comes the opportunity for nutrient recycling. Moreover, the use of RAS to produce larger post-smolts before deployment to sea cages is of interest to the Norwegian aquaculture industry (FAO 2017), and this will further increase the availability of fish sludge.

Fish sludge contains high amounts of macro- and micronutrients. It is commonly used as a substitute for mineral fertilizer on agricultural lands (Celis et al. 2008, Del Campo et al. 2010, Brod et al. 2017) or is transported to biogas plants for biogasification together with other organic side streams (Nnali \& Oke 2013, Aas \& Åsgård 2017). During this process, a proportion of the nutrients (especially organic carbon) are transformed into volatile fatty acids (FAs) and then to methane $\left(\mathrm{CH}_{4}\right)$ and $\mathrm{CO}_{2}$ during anaerobic digestion (Zhang et al. 2014). The residual solid digestate ( $>15 \%$ dry matter, DM) contains useful inorganic nutrients (phosphorous, nitrogen, potassium) and can be used as agricultural fertilizer (Del Campo et al. 2010, Makádi et al. 2012); however, this material could still contain residual proteins and lipids from salmon feed and faeces and thus may be a higher value product than agricultural fertilizer (Nkoa 2014). In addition to the remineralized inorganic nutrients, the digestate also contains a large amount of reworked organic material, now bound in bacteria (Weiland 2010). This might impair bioavailability, as only a fraction of biota possesses the capacity to digest bacteria (Fenchel \& Jørgensen 1977). The ability to digest bacteria is usually found at low trophic levels in animals feeding selectively on bacteria or in detritivorous organisms, such as several species of polychaete worms. As such, Hediste diversicolor may be a well-suited candidate to convert this bacteria- rich solid digestate into high-value biochemicals, as this species is not only known for its superior biochemical composition (Olive 1999, Bischoff et al. 2009, Woulds et al. 2012, 2014), but is also its capacity to digest bacteria (Lucas \& Bertru 1997). Hence, in circular bioproduction involving biogas side streams, this species could act as a key player through conversion of bacteria-rich solid digestate to high value biochemicals such as proteins and n-3 FAs.

$H$. diversicolor has been shown to grow well on aquaculture side streams (Pajand et al. 2017, Marques et al. 2018, Wang et al. 2019, Yousefi-Garakouei et al. 2019). By diverting some of the fish sludge used for biogasification to polychaete production, and combining this with solid biogas digestate (SBD) to serve as a feed source for the polychaete worms could add to the value of both wastes. The aim of the present study was to test the ability of $H$. diversicolor to convert aquaculture waste and biogas digestate into valuable live feed or feed ingredients for fish or shrimp.

\section{MATERIALS AND METHODS}

\subsection{Collection and maintenance of Hediste diversicolor}

H. diversicolor were sampled in October 2017 from the intertidal of Leangbukta bay, Trondheim, Norway, and immediately taken to the laboratory for processing. Upon arrival, non-intact or inactive individuals were discarded; the remaining worms were placed in $200 \mathrm{ml}$ plastic cups with $1 \mu \mathrm{m}$ filtrated seawater (34 ppt salinity) and allowed to evacuate their gut for $2 \mathrm{~h}$ (Wang et al. 2019). Thereafter, the polychaetes were weighed individually (SE 622; VWR) and randomly distributed among 20 groups comprised of 70 individuals each, and placed in experimental tanks. The average initial wet weight (WW) of the worms was $0.26 \pm 0.02 \mathrm{~g}$ (mean $\pm \mathrm{SD}, \mathrm{n}=1400)$.

\subsection{Feeding experiment}

The experiment was carried out at an RAS system (XHAB XR3 stand alone, AQUATIC HABITATS ${ }^{\circledR}$, Pentair Aquatic Eco-Systems) at $16^{\circ} \mathrm{C}$ and under a $16 \mathrm{~h}$ light:8 $\mathrm{h}$ dark photoperiod, controlled by a timer. A layer of washed chamotte $8 \mathrm{~cm}$ in height (granule size: $0.5-2 \mathrm{~mm}$; Alt for Keramikk) was spread on the bottom of the tanks; the depth of water above the substrate was approximately $8 \mathrm{~cm}$. Fresh seawater 
was supplied at a rate of $5 \%$ of the total volume of the system per day.

Worms were fed one of 4 experimental diets that contained a mix of salmon smolt sludge (SS) and SBD. We supplied (1) pure SS (SS100), (2) a 2:1 mix of SS and SBD (SS66), (3) a 1:2 mix of SS and SBD (SS33), and (4) pure SBD (SS0). An additional group was fed fish feed (FF) as a positive control. In total, there were 5 treatments, each with 4 replicates. FF has previously been used as a high-quality feed (1 mm diameter; Ewos Start 040) (Wang et al. 2019). SS was collected from a land-based salmon smolt freshwater RAS (Lerøy Belsvik). The SS ( 1\% DM) was centrifuged at $2800 \times g$ for $10 \mathrm{~min}$ to expel excess water and increase the DM to $23 \%$ before use, and the supernatant was discarded. The SBD (22\% DM) was provided by Biokraft. Because solid digestate usually contains high ammonia concentrations (Gemmeke et al. 2009), the SBD was pretreated by centrifugation $(2800 \times g, 10 \mathrm{~min})$ and the liquid phase discarded before use. The precipitate was thereafter resuspended in distilled water, shaken rigorously, centrifuged again, and the supernatant discarded. This procedure was repeated twice before the precipitate was used as feed for the worms. The worms were fed ad libitum every third day. The feeding corresponded to around $3 \%$ of initial biomass (the total WW of each treatment) per day. Ad libitum feeding was visually confirmed, as there was always feed left on the surface of the sediment in the experimental containers. The feedstuff was thawed, mixed in a $50 \mathrm{ml}$ centrifuge tube with seawater and spread evenly on the sediment surface in order to prevent unequal distribution and competition among the worms as they fed. The system was stopped for $1 \mathrm{~h}$ to let the feed sink.

Physiochemical water quality parameters were measured every $3 d_{i}$ during the experiment mean $( \pm \mathrm{SD})$ values of salinity, $\mathrm{pH}$ and oxygen saturation were $34.5 \pm 0.5 \%, 7.7 \pm 0.1$ and $93.2 \pm 2.86 \%$, respectively (see Table S1 in the Supplement at www.int-res.com/ articles/suppl/q011p551_supp.pdf). Containers were inspected daily, and dead polychaetes visible at the sediment surface were removed immediately.

At the end of the experiment, all worms from each tank were collected and allowed to evacuate their guts for 2-4 h in fresh seawater without sediment. Thereafter, the worms were weighed, freeze-dried and stored in a nitrogen-filled centrifuge tube at $-80^{\circ} \mathrm{C}$ for further analysis. Samples of initial field-collected polychaetes (P0) along with worms from the experiment (hereafter abbreviated FF, SS100, SS66, SS33 and $\mathrm{SS} 0$ ), the experimental diets, FF, SS and SBD were freeze-dried and ground into a powder with a mortar and pestle for elemental and biochemical composition analysis.

\subsection{Elemental and biochemical composition}

The ash, total $\mathrm{C}$ and $\mathrm{N}$ contents, total lipid, FA and amino acid (AA) profiles of the polychaetes and experimental diets were analyzed as described in Wang et al. (2019). In short, ash was determined by combusting samples at $450^{\circ} \mathrm{C}$ in a muffle furnace for $5 \mathrm{~h}$. Total $\mathrm{C}$ and $\mathrm{N}$ were measured using an elemental analyzer.

Total lipids were extracted and determined gravimetrically using the method of Bligh \& Dyer (1959). FAs were esterified to FA methyl esters using $\mathrm{BF}_{3^{-}}$methanol (Metcalfe et al. 1966) and analyzed by means of gas chromatography (Agilent Technologies 7890B) with helium as the carrier gas and a WCOT fused-silica capillary column coated with CP-wax 52CB (Holger CP7713) (Wang et al. 2019).

Protein-bound AAs were determined by HPLC (Agilent Technologies Infinity 1260) coupled with an online post-column derivatization module (Pinnacle PCX; Pickering Laboratories). Extraction of AAs followed methods in Wang et al. (2019). Freeze-dried samples of 0.05-0.1 g were weighted in test tubes and hydrolyzed in $6 \mathrm{M} \mathrm{HCl}$ containing $0.4 \%$ mercaptoethanol at $110^{\circ} \mathrm{C}$ for $24 \mathrm{~h}$. After hydrolysis, samples were filtered (Whatman GF/C, $47 \mathrm{~mm}$ ) and the $\mathrm{pH}$ was adjusted to 2.2 before HPLC analysis. Protein content was calculated from the sum of water-free total AAs (TAAs) (MacLean \& Warwick 2003) divided by a factor of 0.9 in order to account for amino acids that are not fully analyzed by HPLC - such as cysteine and tryptophan (Øie \& Olsen 1997), since these have been estimated to account for approximately $10 \%$ of the TAAs (Watanabe et al. 1983). Carbohydrates were calculated by subtracting ash, protein and lipid content from the total dry weight of the samples.

\subsection{Growth}

The specific growth rate $\left(\mathrm{SGR}, \mathrm{d}^{-1}\right)$ of the polychaetes was calculated by:

$$
\mathrm{SGR}=\left(\ln W_{t}-\ln W_{0}\right) / t
$$

where $W_{t}$ is the mean final biomass $(g, W W), W_{0}$ is the mean initial biomass $(\mathrm{g}, \mathrm{WW})$, and $t$ is experiment duration $(\mathrm{d})$. 


\subsection{Statistics}

All calculations and statistical analyses were conducted using the statistical software program RStudio v.1.1.456. Normality of distribution was tested using the Shapiro-Wilks test. The influence of different dietary treatments on SGR, survival rate and biochemical composition were compared with a 1-way ANOVA, and homogeneity of variances was tested with a Levene's test. Tukey's HSD and Bonferroni correction tests were used for post hoc analysis. Statistical significance was set to $\mathrm{p}<0.05$. A principal component analysis (PCA) was conducted for representation of AA or FA composition among the treatments. Before PCA analyses, percentage data were transformed following the equation:

$$
\operatorname{transf} f_{\text {data }}=180 / \pi \times \sin ^{-1}(\sqrt{\text { data } / 100})
$$

Linear regression was used evaluate the dietary correlations between the polychaetes and their diets.

\section{RESULTS}

\subsection{Biochemical composition of diets}

\subsubsection{Proximate composition of diets}

The proximate composition of the experimental feeds including moisture, ash, protein, lipids and carbohydrates are shown in Table 1 . The protein content of FF was approximately twice as high as that of SS and SBD (ANOVA, $F_{2,6}=2876, \mathrm{p}=1.13 \times 10^{-9}$; Tukey's HSD, $\mathrm{p}<0.001)$. FF and SS contained similar and significantly higher lipid levels (22.9 and 20.1\%, respectively) than SBD (8.7\%; ANOVA, $F_{2,6}=45.27$, $\mathrm{p}<0.001$; Tukey's HSD, FF, SS100 > SBD, p < 0.001).
Conversely, SBD contained significantly higher amounts of carbohydrates than SS and FF, and the carbohydrate level in SS was higher than that in FF (ANOVA, $F_{2,6}=86.09, \mathrm{p}<0.001$; Tukey's HSD, SBD $>$ SS, $\mathrm{p}=0.04 ; \mathrm{SBD}>\mathrm{FF}, \mathrm{p}<0.001 ; \mathrm{SS}>\mathrm{FF}, \mathrm{p}<0.001)$.

\subsubsection{AA composition of the diets}

The AA concentration and composition in the experimental diets are shown in Table S2. AA concentration was about 2 times higher in FF than in SS and SBD. SS had higher levels of the essential AAs (EAAs) isoleucine, leucine and valine compared to FF and SBD. FF had a higher TAA content and higher relative amounts of glutamine/glutamic acid, proline and nonessential AAs (NEAAs), but lower isoleucine, leucine, phenylalanine, valine and alanine compared to the other diets. SBD was higher in alanine and glycine than FF and SS.

\subsubsection{FA composition of the diets}

SS and FF lipid contents did not show an obvious difference, whereas SBD had much lower lipids than the other diets (Table S2). FF contained higher levels of C22:1n-9, docosahexaenoic acid (DHA; C22:6n-3) and n-3 polyunsaturated fatty acids (n-3 PUFAs) than SS and SBD. The FAs C18:1n-9, C18:2 n-6 and C18:3n-3 were higher in SS than in FF and SBD. SBD consisted of lower amounts of DHA and C18:3n-3 and no eicosapentaenoic acid (EPA; C20:5n-3) or any other n-3 PUFAs; hence, the total content of n-3 PUFAs was lower in SBD than in FF and SS. SBD also had an absence of the essential FA arachidonic acid (ARA; C20:4n-6). Saturated FAs (SFAs) in SBD were

Table 1. Proximate components of the different Hediste diversicolor diets used in the $30 \mathrm{~d}$ feeding trial, shown as either \% dry matter (DM), $\mathrm{mg} \mathrm{g}^{-1}$ of $\mathrm{DM}$ or $\%$ wet weight $(\mathrm{WW})$ (mean $\pm \mathrm{SD} ; \mathrm{n}=3$ replicates). FF: fish feed; SS: smolt sludge; SBD: solid biogas digestate. Numbers following treatment type indicate feed ratio (SS100: pure SS; SS66: 2:1 mix of SS and SBD; SS33: 1:2 mix of SS and SBD SS0: pure SBD). Superscripts denote statistically significant differences between FF, SS100 and SS0 treatments. SS66 and SS33 were calculated from the mean and SD of SS100 and SS0

\begin{tabular}{|c|c|c|c|c|c|}
\hline Composition & FF & $\begin{array}{c}\text { SS100 } \\
\text { (1:0 SS:SBD) }\end{array}$ & $\begin{array}{c}\text { SS66 } \\
(2: 1 \mathrm{SS}: \mathrm{SBD})\end{array}$ & $\begin{array}{c}\text { SS33 } \\
(1: 2 \mathrm{SS}: \mathrm{SBD})\end{array}$ & $\begin{array}{c}\text { SS0 } \\
(0: 1 \mathrm{SS}: \mathrm{SBD})\end{array}$ \\
\hline $\mathrm{C}\left(\mathrm{mg} \mathrm{g}^{-1} \mathrm{DM}\right)$ & $449.3 \pm 29.30$ & $409.9 \pm 2.76$ & $400.1 \pm 2.95$ & $390.3 \pm 4.70$ & $380.5 \pm 6.92$ \\
\hline $\mathrm{N}\left(\mathrm{mg} \mathrm{g}^{-1} \mathrm{DM}\right)$ & $94.67 \pm 0.52$ & $49.66 \pm 1.38$ & $49.85 \pm 0.93$ & $50.03 \pm 0.53$ & $50.22 \pm 0.38$ \\
\hline Moisture (\% WW) & $8.46 \pm 0.42$ & $77.35 \pm 0.18$ & $77.70 \pm 0.14$ & $78.05 \pm 0.16$ & $78.40 \pm 0.22$ \\
\hline Ash (\% DM) & $9.08 \pm 0.06$ & $19.21 \pm 0.09$ & $21.11 \pm 0.19$ & $23.02 \pm 0.35$ & $24.92 \pm 0.53$ \\
\hline Protein (\% DM) & $44.33 \pm 0.66^{\mathrm{a}}$ & $21.06 \pm 0.23^{\mathrm{b}}$ & $21.06 \pm 0.18$ & $21.07 \pm 0.20$ & $21.07 \pm 0.27^{b}$ \\
\hline Lipids (\% DM) & $22.86 \pm 0.50^{\mathrm{a}}$ & $20.10 \pm 3.15^{\mathrm{a}}$ & $16.29 \pm 2.13$ & $12.48 \pm 1.26$ & $8.67 \pm 1.04^{\mathrm{b}}$ \\
\hline Carbohydrates (\% DM) & $23.73 \pm 1.06^{\mathrm{c}}$ & $39.62 \pm 3.39^{b}$ & $41.53 \pm 2.27$ & $43.43 \pm 1.23$ & $45.34 \pm 0.72^{\mathrm{a}}$ \\
\hline
\end{tabular}


significantly higher than in FF and SS. Moreover, SBD had higher monounsaturated FAs (MUFAs) and an extremely low level of PUFAs $(2.8 \%$ of total FAs, TFA).

\subsection{Dietary effects on growth and survival}

The worms fed FF had a significantly higher SGR compared to worms fed the other diets (mean \pm SD: $0.018 \pm 0.003 \mathrm{~d}^{-1} ;$ ANOVA, $F_{4,15}=22.88, \mathrm{p}=3.07 \times$ $10^{-6}$; Tukey's HSD, $\mathrm{p}<0.001$ ), whereas there were no significant differences in SGRs among the other treatments (Fig. 1). The survival rate ranged from $82-92 \%$ among treatments, and there were no significant dietary effects on mortality (Fig. 2; ANOVA, $F_{4,15}=1.80, \mathrm{p}=0.182$ ).

\subsection{Biochemical composition of polychaetes}

\subsubsection{Proximate polychaete composition}

The protein content of Hediste diversicolor fed different diets ranged from $42.1-47 \%$ DM. The protein content in SS100 was significantly lower than that in the FF and SS0 treatments (ANOVA, $F_{5,17}=5.22, \mathrm{p}=$ 0.004; Bonferroni correction test, SS100 < FF, p = 0.015 ; SS100 < SS0, p = 0.005), and there were no significant differences between worms from the other treatments and the P0 specimens (Table 2). Hence, the protein content in $H$. diversicolor was not affected by diet, assuming adequate feed supply. The highest lipid content was found in worms fed exclusively SS (i.e. SS100) and FF, and these worms contained the same lipid levels as the P0 specimens (ANOVA, $F_{5,18}=22.96, \mathrm{p}<0.001$ ). The lipid content in polychaetes appeared to decrease as the proportion of SS fed decreased, and the lowest lipid content was found for worms fed exclusively SBD (Tukey's HSD test, SS100 > SS66, SS33, SS0, p = 0.021, p < $0.001, \mathrm{p}<0.001$; and SS66 $>\mathrm{SS} 0, \mathrm{p}<0.001$ ). However, there were no significant differences in lipid content between worms fed SS33 and SS66 and the P0 worms. Water content was significantly lower for worms in both FF and SS100 treatments compared to SS0 and P0 worms (ANOVA, $F_{5,18}=7.89, \mathrm{p}<0.001$; Tukey's HSD test, FF and SS100 > P0, p $=0.001$, $0.004 ; \mathrm{FF}, \mathrm{SS} 100>\mathrm{SS} 0, \mathrm{p}=0.005,0.02)$. The lowest ash content was found for P0 worms (ANOVA, $F_{5,19}=$ $20.03, p<0.001$ ), whereas worms fed FF had a significantly lower ash content compared to all treatments that included SS in the diet (ANOVA, $F_{5,19}=20.03$,

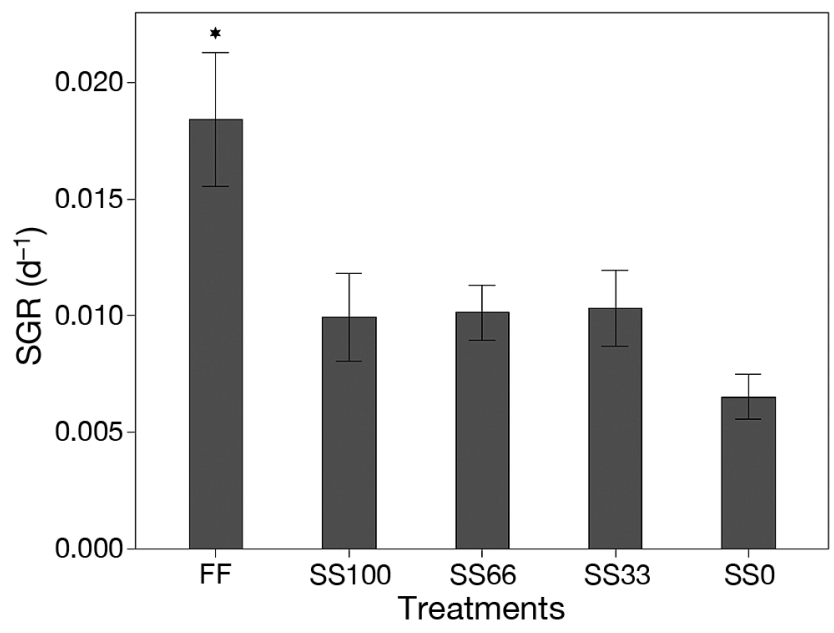

Fig. 1. Specific growth rate $\left(\mathrm{SGR}, \mathrm{d}^{-1}\right)$ of Hediste diversicolor fed with different diets (see Table 1 for treatment definitions). Data are mean \pm SD. ${ }^{*}$ indicates significant difference at $\alpha=0.05$

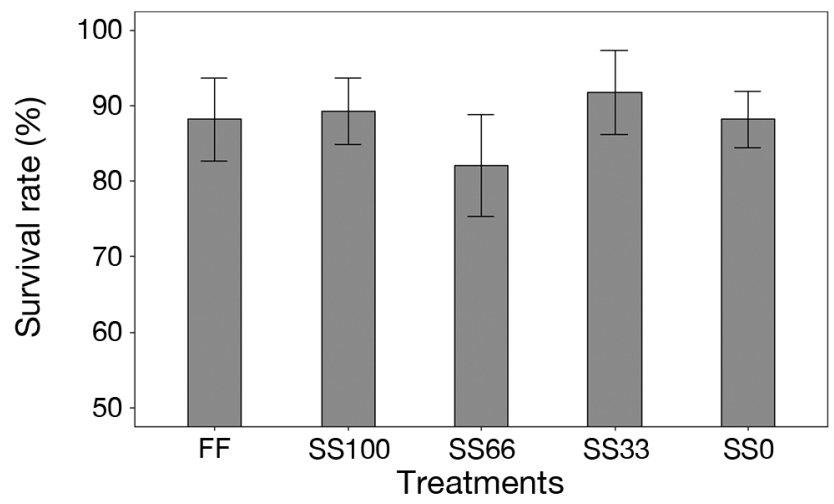

Fig. 2. Survival (\%) of Hediste diversicolor fed different diets (see Table 1 for treatment definitions) for a period of $30 \mathrm{~d}$ Data are mean $\pm \mathrm{SD}$

$\mathrm{p}<0.001$; Bonferroni correction test, FF $<$ SS100, SS66, SS33; $\mathrm{p}=0.004,0.018,0.009$ ).

There was a positive correlation between the total lipid content of the diets and that in the polychaetes $\left(R^{2}=0.89, p>0.001\right.$; Fig. 3). For the treatments where the dietary lipid content was lower than the lipid content in the P0 polychaetes (mean \pm SD: $<14.62 \pm$ $0.43 \mathrm{~g}$ per $100 \mathrm{~g} \mathrm{DM}$ ), as found for the SS33 and SS0 treatments, the total lipid content in the polychaetes reached levels surpassing their diets but were still lower than the initial levels. The lipid retention efficiency in $H$. diversicolor found for this study was positive. When the lipid content in the experimental diets was less than $13.7 \%$ of DM, the worms accumulated lipids, whereas above this level, the worms retained less than they got from their food. In general, when the total lipid of the diets increased by $1 \%$ 
Table 2. Proximate nutritional composition (mean $\pm \mathrm{SD} ; \mathrm{n}=4$ replicates) of Hediste diversicolor produced on different diets over a period of $30 \mathrm{~d}$. WW: wet weight; DM: dry mass; P0: field-collected polychaetes; see Table 1 for treatment definitions. Different superscript letters within columns denote significant differences $(p<0.05)$ in descending order

\begin{tabular}{|lcccccc|}
\hline $\begin{array}{l}\text { Proximate } \\
\text { composition }\end{array}$ & FF & SS100 & SS66 & SS33 & SS0 & P0 \\
\hline Moisture (\% WW) & $79.16 \pm 0.54^{\mathrm{c}}$ & $79.30 \pm 0.43^{\mathrm{c}}$ & $79.59 \pm 0.34^{\mathrm{bc}}$ & $79.83 \pm 0.35^{\mathrm{abc}}$ & $80.34 \pm 0.04^{\mathrm{ab}}$ & $80.52 \pm 0.46^{\mathrm{a}}$ \\
Ash (\% DM) & $11.10 \pm 1.26^{\mathrm{b}}$ & $16.66 \pm 2.88^{\mathrm{a}}$ & $15.88 \pm 1.51^{\mathrm{a}}$ & $16.26 \pm 0.88^{\mathrm{a}}$ & $14.15 \pm 1.44^{\mathrm{ab}}$ & $6.54 \pm 2.75^{\mathrm{c}}$ \\
Protein (\% DM) & $46.39 \pm 0.91^{\mathrm{a}}$ & $42.09 \pm 1.46^{\mathrm{b}}$ & $44.21 \pm 1.80^{\mathrm{ab}}$ & $44.29 \pm 1.66^{\mathrm{ab}}$ & $46.95 \pm 1.45^{\mathrm{a}}$ & $45.30 \pm 1.82^{\mathrm{ab}}$ \\
Lipid (\% DM) & $15.43 \pm 0.94^{\mathrm{ab}}$ & $16.21 \pm 0.82^{\mathrm{a}}$ & $14.53 \pm 0.81^{\mathrm{bc}}$ & $13.17 \pm 0.44^{\mathrm{cd}}$ & $11.83 \pm 0.46^{\mathrm{d}}$ & $14.62 \pm 0.43^{\mathrm{abc}}$ \\
Carbohydrates (\% DM) & $27.08 \pm 0.82$ & $25.04 \pm 2.99$ & $25.38 \pm 1.38$ & $26.29 \pm 1.88$ & $27.06 \pm 2.24$ & $37.30^{*}$ \\
${ }^{*}$ This value was pooled, calculated from mean ash, protein, lipid and dry weight & & \\
\hline
\end{tabular}

in the range from $8-20 \mathrm{~g}$ per $100 \mathrm{~g}$ of $\mathrm{DM}$, the total lipids in the worms increased by approximately $0.38 \%$.

\subsubsection{Dietary effects on AA composition in $H$. diversicolor}

A PCA was conducted in order to identify differences in AA composition in $H$. diversicolor among treatments and to assess which AAs were decisive for these differences (Fig. 4). PC1 explained $58.2 \%$ of the variation between treatments; PC2 explained a further $18.6 \%$. The PCA showed clear differences

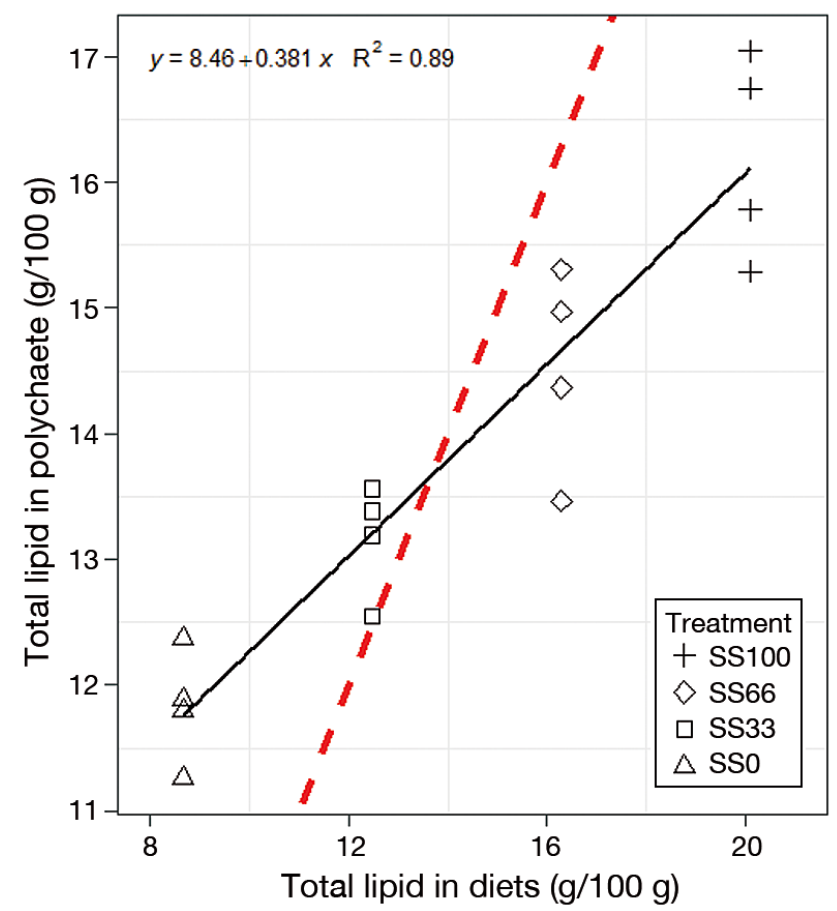

Fig. 3. Relationship between the total lipid content of Hediste diversicolor and total lipids in experimental diets. Dotted red line: equality between the total lipid in diets and in polychaetes. See Table 1 for treatment definitions between the P0 worms and worms from the experimental treatments. Both the AA composition (Table S4) and the factor loadings indicated that the differences were caused by higher relative amounts of alanine, leucine and EAAs, and lower amounts of asparagine/ aspartic acid, glutamine/glutamic acid, proline and NEAAs. The worms fed FF showed highly negative PC2 scores that separated them from the other treatments, mainly due to relatively higher methionine and lysine levels. We tested for linear relationships between the amino acid concentrations in the polychaetes and that in diets with different mixing ratios of SS:SBD and found no evidence for an influence of dietary treatment for any AA.

\subsubsection{Dietary effects on FA composition in $H$. diversicolor}

The PCA analysis showed that the FA composition in the polychaetes was affected by their diet, and PC1 and PC2 together explained $88 \%$ of the variance (Fig. 5). Total lipid content was significantly lower for the polychaetes fed SS0 compared to the P0 worms, whereas there were no differences between P0 polychaetes and the remaining treatments. The data in Table S5 and the PCA revealed that P0 and SS0 had higher composition of SFAs, C20:5n-3, C16:0 and C18:0, but conversely lower TFAs, C18:1n-9, C22:1n9 and C18:2n-6. These FAs in the SS100 and SS66 treatments were opposite to that in the P0 and SS0 treatments. Worms in the FF treatment had higher levels of C14:0, C16:1n-7 and C22:6n-3 and lower levels of C18:3n-3 and C22:5n-3, but conversely, the SS33 treatment had lower levels of these FAs.

Linear regression analyses were carried out in order to evaluate the relationship between the FAs recovered in the polychaetes and the dietary FA composition stemming from the different mixing ratios of SS:SBD (Fig. 6). There were strong positive correla- 


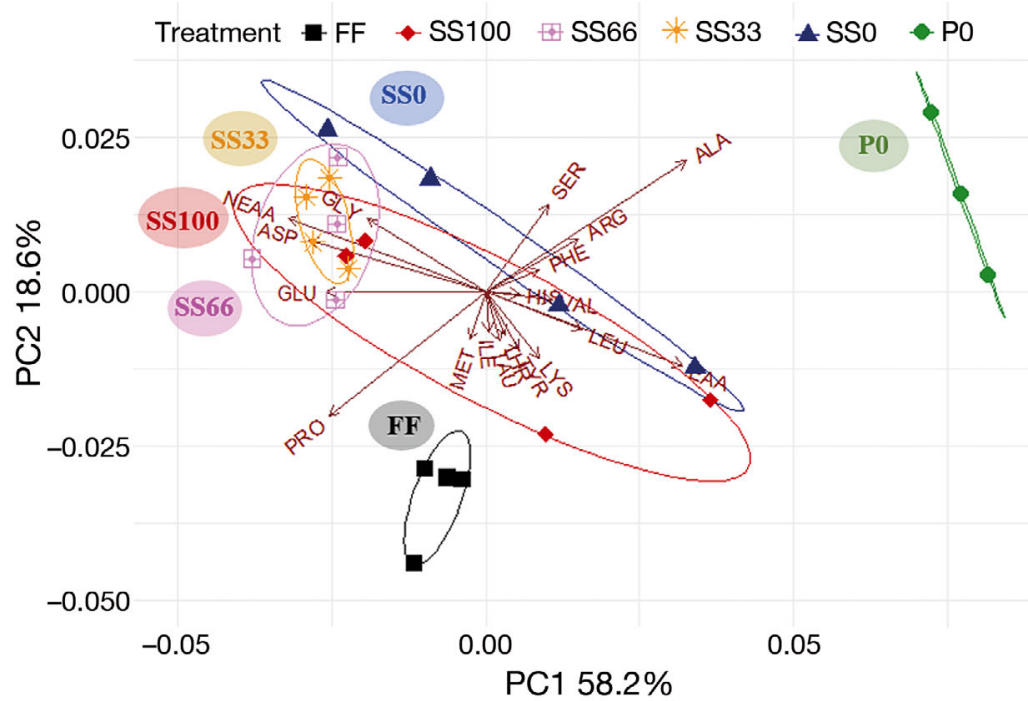

Fig. 4. PCA of amino acids, including essential (EAA) and nonessential amino acids (NEAA) (\% of the total amino acids), in Hediste diversicolor fed different feeds over an experimental period of $30 \mathrm{~d}$. Data were arcsine transformed.

See Table 1 for treatment definitions; P0: field-collected polychaetes

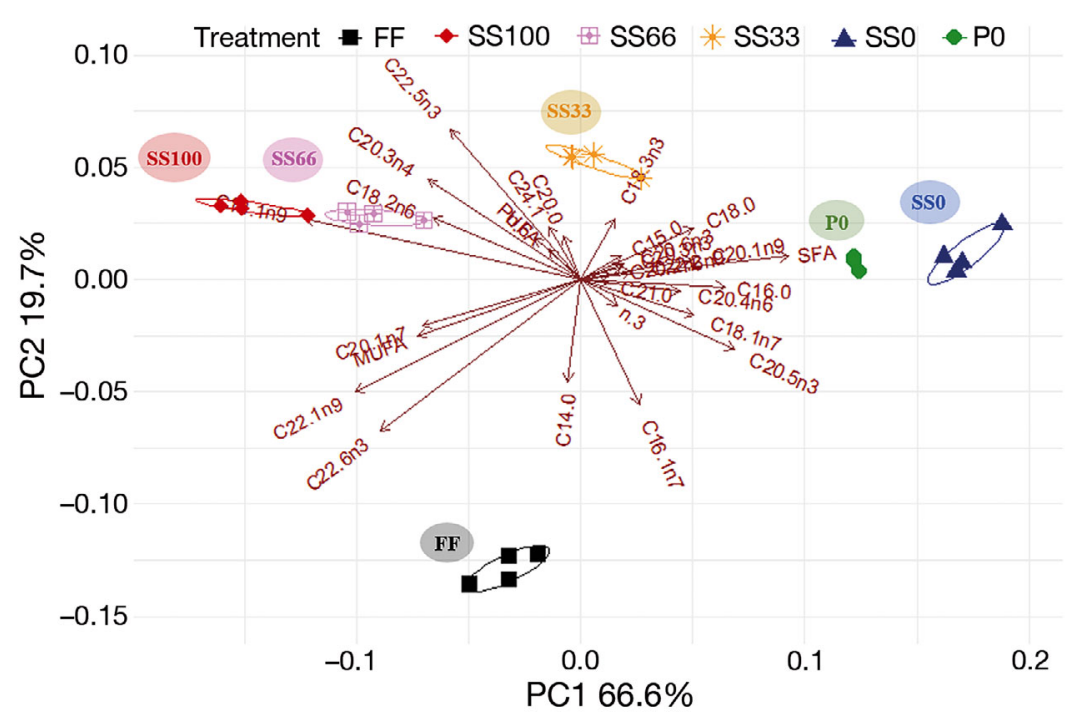

Fig. 5. PCA of fatty acids (\% of total fatty acids) of Hediste diversicolor fed different feeds; data were arcsine transformed. Saturated, monounsaturated, polyunsaturated and total fatty acids were included. See Fig. 1 for treatment definitions; P0: field-collected polychaetes

tions found for C16:0, C18:0, C18:1n-7, C18:1n-9, C18:2n-6, C22:5n-3, DHA, n-3/n-6, SFAs, TFAs, PUFAs and n-6 PUFAs, while there were strong negative correlations for ARA, EPA and MUFA levels in the diet. The results showed that by supplementing SS one can expect a relative increase in the C18:1n9, C18:2n-6, C22:5n-3, DHA, TFA, MUFA and PUFA levels in polychaete tissues, whereas increasing the amount of SBD will increase the relative amounts of C16:0, C18:0, C18:1n-7, n-3/n-6, ARA, EPA and SFAs.

\section{DISCUSSION}

In this study, we demonstrated for the first time that Hediste diversicolor can grow exclusively on an SBD diet, obtaining an increased level of lipids and a balanced AA profile, and can therefore be developed as a potential feed ingredient. Moreover, we showed that although polychaete growth rates were not significantly improved by adding SS to the SBD in the diet, this significantly affected the total lipid and FA content and altered the relative content of FAs in the polychaetes. Similar results have been reported when SBD was fed to several terrestrial animal species. Earthworms, for example, can successfully convert biogas digestate into valuable products (Garg et al. 2006, Suthar 2010). Larval black soldier flies Hermetia illucens reared with biogas digestate showed results similar to ours: larvae grew on SBD, but flies fed high-quality diets (chicken feed) had 2 to 2.5 times higher gain in wet weight (Spranghers et al. 2017). Other studies have shown that pig feed can be supplemented with up to $15 \%$ of biogas sludge without any visible negative effects on pig growth rate, serum biochemistry or meat quality (Xu et al. 2017). Thus, SBD can be used for a range of species, but can be improved with the addition of other feed components.

\subsection{Polychaete growth}

The SGR of polychaetes fed FF was nearly 1.8 times higher than all other treatments. Feeding different ratios of SS:SBD did not significantly affect SGR, though polychaetes grew slowest when fed SBD exclusively. We hypothesize that the protein content of the diets, which was 2.1 times higher in FF than in SS and SBD, was the main cause for the different SGRs. This is in accordance with Santos et al. (2016) and Wang et al. (2019), who showed a positive correlation between dietary protein content and SGR for $H$. diversicolor.

More interesting in the current study was that worms receiving only SBD grew slowest in the experiment, 

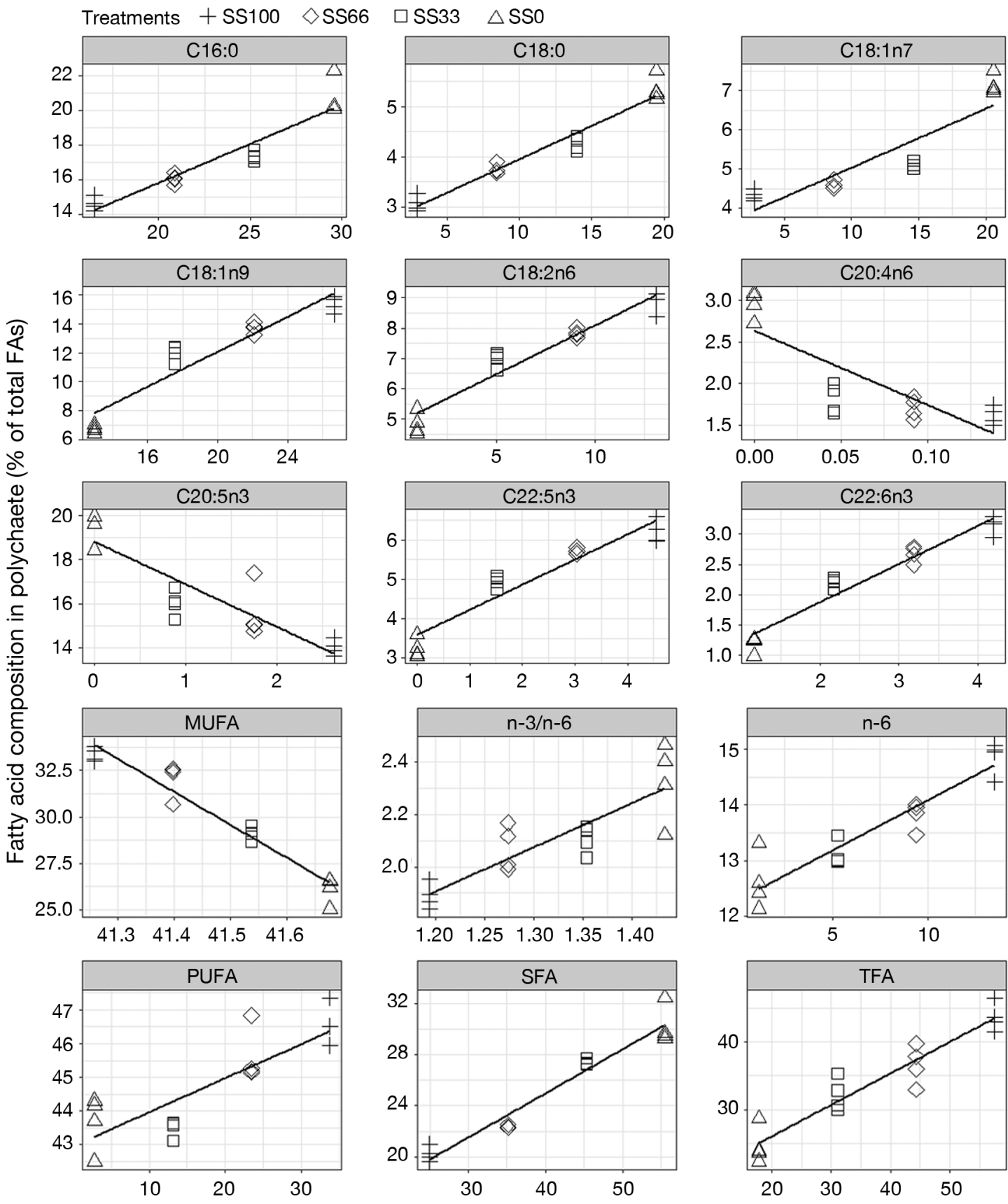

Fatty acid composition in diets (\% of total FAs)

Fig. 6. Relationship between fatty acid (FA) composition of the experimental diet and fatty acid composition of Hediste diversicolor after the $30 \mathrm{~d}$ experimental period. See Fig. 1 for treatment definitions; MUFA: monounsaturated FA; PUFA: polyunsaturated FA; SFA: saturated fatty acid; TFA: total FA. The FA values in each diet treatment are the mean values of each diet; SS66 and SS33 were calculated according to the ratio of SS:SBD

but as soon as one-third of the digestate was replaced by SS, the worms grew at a rate comparable to those grown on SS exclusively, which means that even though a combination of side streams was not able to achieve growth comparable to high-quality fish feeds, side streams can complement each other. However, we can not rule out that worms fed mixtures were exclusively feeding on SS. This, however, is unlikely as the PCAs of both fatty FAs and AAs showed grouping within treatments but differences between treatments, clearly indicating that both food sources were being utilized. 


\subsection{Effects of diet on polychaete protein and AA composition}

Protein and EAA composition plays an important role in fish performance and growth (Khalili Tilami \& Sampels 2018). The polychaetes produced in our study had a protein content of $42-47 \%$ of DM, which is in line with the dietary protein requirements for several shrimp (i.e. Penaeus monodon, P. indicus, P. merguiensis etc.) and fish species such as tilapia Oreochromis niloticus, grass carp Ctenopharyngodon idellus and rainbow trout Oncorhynchus mykiss (Hasan 2000).

In addition to adequate protein levels, a wellbalanced mixture of amino acids is an effective way of satisfying these requirements while using less protein (Wilson 2003). As hydrolysis was used for the AA analysis, our comparisons did not include cysteine (which can only be analyzed as dipeptide cysteine by this method) or tryptophan (which is completely destroyed by hydrolysis and hence not detectable). Except for tryptophan, the EAA content of $H$. diversicolor from all treatments matched the EAA requirements of The lipid content of polychaetes fed mixtures of SS and SBD ranged from $12-16 \%$. The lipid content of polychaetes fed pure SBD was significantly lower than that of the worms initially, which shows that diets with lipid content greater than $8.7 \%$ of DM may be required to maintain the initial lipid level (Tacon 1987 , Hasan 2000), and moreover, AAs were present in high levels in the polychaetes from all treatments (Table S6), indicating that $H$. diversicolor can maintain high EAA content while utilizing SS and SBD.

\subsection{Effects of diet on polychaete lipid and FA composition}

Lipids typically constitute $7-15 \%$ of fish feeds, and their main functions are to provide energy, essential fatty acids and a medium to transport fat-soluble vitamins (Craig et al. 2017). The lipid content of the polychaetes in this study was positively correlated with dietary lipid levels. The lipid content in the polychaetes fed with different ratios of SS:SBD increased along with the proportion of SS provided due to a higher lipid content in the sludge (20.1\% of DM) compared to the SBD (8.6\% of DM). The lipid content of polychaetes fed mixtures of SS and SBD ranged from $12-16 \%$. The lipid content of polychaetes fed pure SBD was significantly lower than that of the worms initially, which shows that diets with lipid content greater than $8.7 \%$ of DM may be required to maintain the initial lipid level.
FAs, especially n-3 long-chain (lc)PUFAs, are significant factors for feed efficiency, growth and reproductive performance of aquatic animals (Glencross 2009), and they are also important to human health. FA composition of the polychaetes was affected by the dietary FA profiles. The diets were not that different with respect to MUFA content, whereas the SFA content was significantly higher in the SBD and the PUFA content significantly lower compared to the SS. Interestingly, the FA content of the polychaetes only mirrored these differences in SFAs, but not in MUFAs or PUFAs, as the relative composition of the MUFAs and PUFAs were within the same range for all treatments. Despite a 12-fold lower PUFA content in the SBD compared to the SS and FF diets, worms fed on SBD exclusively showed similar relative PUFA levels as those in the other treatments. Although the SBD-fed polychaetes increased in biomass by $28 \%$ during the experiment, in absolute terms they lost about $4.2 \%$ of the TFAs compared to their initial content. The DHA content in polychaete tissues was associated with that of the feed they consumed. In this study, increasing the proportion of SBD caused an increase in lcPUFAs like ARA and EPA.

Plant and livestock oils are currently being used to replace fish oils in aquafeed production (Tacon et al. 2009), but they lack essential FAs such as ARA, EPA and DHA and contain lower or imbalanced amounts of PUFAs. Glencross (2009) showed that some fish, like turbot Scophthalmus maximus and red seabream Pagrus major, have limited ability to elongate essential FAs of C18:2 n-6 and C18:3 n-3 into their respective lcPUFAs, so they require them from their diet. Furthermore, the amounts of ARA, EPA and DHA strongly influence the growth and survival of fish and shrimp (Tocher 2010, Castro et al. 2018). The polychaetes produced in our experiment were high in PUFAs, with 28-29\% n-3 PUFA (of the TFA, anchovy $30 \%$, cod liver $24 \%$, jack mackerel $26 \%$ ) and contained all the essential FAs and can therefore serve as an important essential FA source for aquafeed production (Table S7).

\subsection{Suitability of polychaetes produced on aquaculture and biogas side streams as feed ingredients}

The ultimate aim of this study was to grow worms as a potential fish meal and oil substitute or as a component of e.g. a functional shrimp diet. The polychaetes grew best on FF, which was not surprising. The superiority of FF over side streams as feed for polychaete worms has been shown in previous studies; e.g. for $H$. 
diversicolor reared on salmon feeds or SS (Wang et al. 2019), Nereis virens fed either halibut feed or halibut feces (Brown et al. 2011) and Perinereis nuntia vallate fed on either Japanese flounder feed or flounder waste (Honda \& Kikuchi 2002). However, from a recycling point of view, it is more interesting that in the 3 abovementioned studies, worms fed on the fish farm side stream products grew well, opening opportunities for secondary bioproduction. The same pattern - highquality feeds resulting in high yields, undigested side streams showing intermediate growth and digestatefed organisms showing positive, but poorer growth than those reared on the latter feed sources - has also been reported for black soldier fly larvae (Spranghers et al. 2017). The authors of that study concluded that black soldier fly prepupae reared on different side streams could be a potential protein source for animal feeds, but also mentioned that prepupae grown on digestate could be problematic to use due to their elemental composition, as they are very rich in ash and calcium. Clearly, biosecurity must be considered very carefully, as polychaetes have been shown to be a potential vector for the white spot syndrome virus (WSSV) (Vijayan et al. 2005, Verreth et al. 2014, Haryadi et al. 2015).

\subsection{Regulatory and economic constraints}

Feed ingredients should be produced outside of the human food supply chain and without negative impact on the environment in order to develop a sustainable bio-economy. However, currently, the novel production of polychaetes and other low-trophic level species cannot replace other cheaper sources of protein e.g. soy extract. Furthermore, technology for intensive production of polychaetes at an industrial scale does not yet exist, making it challenging to estimate energy requirements and perform techno-economic and life-cycle analyses for such feed production. We believe that innovations, regulatory changes and consumer demands, together with other drivers, can change this.

Special attention must be paid to legal issues. Based on past crises, such as the bovine spongiform encephalitis epidemic caused by irresponsible practices in agriculture, the European Union set regulations in place intended to prevent such preventable outbreaks (Regulation EC No. 999/2001). The use of sludge from land-based fish farming as well as the use of SBD (depending on the feedstock used for biogas production) as a source of nutrition for animals are clearly regulated. Following current regulations, animals and animal byproducts produced on sludge from fish farms are not allowed as ingredients in animal feeds (Regulation EC Nos. 1096/2009 and 767/ 2009); hence, polychaetes produced as suggested in this paper cannot serve as ingredients for aquafeeds under current EU regulations. However, in contrast to past practices which led to these regulations (such as feeding meat- and bonemeal to young calves, which are herbivorous), fish waste is a natural part of the diet of detritivourus polychaetes, and current regulations might be reconsidered with new species being farmed. Clearly, the regulations in place make sense and are set up to ensure animal and consumer health; however, they are not made with animals such as polychaetes, gammarid shrimps or insects in mind. Recent developments of insect farming, for example, led to a change in EU regulations authorizing the use of insect proteins in feed for farmed animals, demonstrating that new approaches can lead to adjusted regulations. This change of regulation was based on an effort to ensure the biosafety of the insect protein and was only implemented after a careful examination of all risks (EFSA Scientific Committee 2015). However, Annex III to Regulation EC No. 767/2009 prohibits the use of faeces as feed, even though these materials are used in other parts of the world for insect production. As fish faeces are a natural part of the polychaete diet, a reconsideration of Annex III to Regulation EC No. 767/2009 might be timely to ensure proper use of side streams of future expanding land-based aquaculture, and at the same time produce proteins and lipids for aquafeed operations.

\section{CONCLUSIONS}

The present study showed that Hediste diversicolor can convert low-value biogas residues and SS into high-quality ingredients for aquafeeds. Low-lipid feed sources such as SBD can be enhanced by mixing with higher lipid-containing aquaculture side streams such as SS to yield higher lipid levels in the produced polychaetes. FA profiles of the polychaetes are affected by their diet. By adding SS to SBD, the levels of lcPUFAs like DPA and DHA can be increased.

Acknowledgements. The work was supported by the Research Council of Norway (RCN) IPN-project COMPLETE (\#256281), the Strategic Institute Project LOWTROPHIC: production and processing of new marine ingredients from low trophic species at SINTEF Ocean and the RCN project Cultivation of Polychaeta as raw material for feed (POLYCHAETE, \#280836). The experimental work was carried out within the framework of the national research infrastructure 'Norwegian Center for Plankton Technology' 
(\#245937/F50). The authors thank Rasa Slizyte, Åsmund Johansen and Kjersti Rennan Dahl for their kind help. H.W. acknowledges financial support from the China Scholarship Council (\#201506220184).

\section{LITERATURE CITED}

Aas TS, Åsgård TE (2017) Estimated content of nutrients and energy in feed spill and faeces in Norwegian salmon culture. Rapportserie 19/2017. Nofima, Tromsø

Bergheim A, Drengstig A, Ulgenes Y, Fivelstad S (2009) Production of Atlantic salmon smolts in Europe-current characteristics and future trends. Aquacult Eng 41:46-52

Bischoff AA, Fink P, Waller U (2009) The fatty acid composition of Nereis diversicolor cultured in an integrated recirculated system: possible implications for aquaculture. Aquaculture 296:271-276

Bligh EG, Dyer WJ (1959) A rapid method of total lipid extraction and purification. Can J Biochem Physiol 37:911-917

Brennan NB (2018) Studying the waste recycling potential of naturally occurring polychaetes on benthic trays under a Norwegian fish farm. MSc thesis, University of Bergen

Brod E, Oppen J, Kristoffersen AØ, Haraldsen TK, Krogstad T (2017) Drying or anaerobic digestion of fish sludge: nitrogen fertilisation effects and logistics. Ambio 46:852-864

* Brown N, Eddy S, Plaud S (2011) Utilization of waste from a marine recirculating fish culture system as a feed source for the polychaete worm, Nereis virens. Aquaculture 322-323:177-183

Castro O, Burri L, Nunes A (2018) Astaxanthin krill oil enhances the growth performance and fatty acid composition of the Pacific whiteleg shrimp, Litopenaeus vannamei, reared under hypersaline conditions. Aquacult Nutr 24:442-452

Celis J, Sandoval M, Barra R (2008) Plant response to salmon wastes and sewage sludge used as organic fertilizer on two degraded soils under greenhouse conditions. Chil J Agric Res 68:274-283

Clarke R, Bostock J (2017) Regional review on status and trends in aquaculture development in Europe-2015. FAO Fisheries and Aquaculture Circular No.1135/1. FAO, Rome

Craig S, Helfrich LA, Kuhn D, Schwarz MH (2017) Understanding fish nutrition, feeds, and feeding. Publication 420-256. Virginia State University, Petersburg, VA

* Dalsgaard J, Lund I, Thorarinsdottir R, Drengstig A, Arvonen K, Pedersen PB (2013) Farming different species in RAS in Nordic countries: current status and future perspectives. Aquacult Eng 53:2-13

Del Campo LM, Ibarra P, Gutièrrez X, Takle HR (2010) Utilization of sludge from recirculation aquaculture systems. Rapportserie 9/2010. Nofima, Tromsø

EC (European Commission) (2014) European Resource Efficiency Platform (EREP): manifesto and policy recommendations. European Commission, Brussels

EFSA Scientific Committee (2015) Risk profile related to production and consumption of insects as food and feed. EFSA J 13:4257

Fenchel TM, Jørgensen BB (1977) Detritus food chains of aquatic ecosystems: the role of bacteria. In: Alexander M (ed) Advances in microbial ecology. Springer, New York, NY, p 1-58

Garg VK, Kaushik P, Dilbaghi N (2006) Vermiconversion of wastewater sludge from textile mill mixed with anaero- bically digested biogas plant slurry employing Eisenia foetida. Ecotoxicol Environ Saf 65:412-419

Gemmeke B, Rieger C, Weiland P (2009) Biogas-Messprogramm II:61 Biogasanlagen im Vergleich. von Thuenen Institute/Institut für Agrartechnologie und Biosystemtechnik, FNR, Gülzow

Glencross BD (2009) Exploring the nutritional demand for essential fatty acids by aquaculture species. Rev Aquacult 1:71-124

* Gorle J, Terjesen BF, Mota VC, Summerfelt S (2018) Water velocity in commercial RAS culture tanks for Atlantic salmon smolt production. Aquacult Eng 81:89-100

Hamilton HA, Brod E, Hanserud OS, Gracey EO and others (2016) Investigating cross-sectoral synergies through integrated aquaculture, fisheries, and agriculture phosphorus assessments: a case study of Norway. J Ind Ecol 20:867-881

*Haryadi D, Verreth JA, Verdegem MC, Vlak JM (2015) Transmission of white spot syndrome virus (WSSV) from Dendronereis spp. (Peters) (Nereididae) to penaeid shrimp. J Fish Dis 38:419-428

Hasan M (2000) Nutrition and feeding for sustainable aquaculture development in the third millennium. In: Subasinghe RP, Bueno P, Phillips MJ, Hough C, McGladdery $\mathrm{SE}$, Arthur JR (eds) Technical proceedings of the conference on aquaculture in the third millennium, 20-25 February 2000, Bangkok. NACA, Bangkok, p 193-219

*Honda H, Kikuchi K (2002) Nitrogen budget of polychaete Perinereis nuntia vallata fed on the feces of Japanese flounder. Fish Sci 68:1304-1308

Kadowaki S, Kitadai Y (2017) Advantages of environmentally sound poly-eco-aquaculture in fish farms. In: Takeuchi T (ed) Application of recirculating aquaculture systems in Japan. Springer, Tokyo, p 267-278

Khalili Tilami S, Sampels S (2018) Nutritional value of fish: lipids, proteins, vitamins, and minerals. Rev Fish Sci Aquacult 26:243-253

Kucas F, Bertru G (1997) Bacteriolysis in the gut of Nereis diversicolor (OF Müller) and effect of the diet. J Exp Mar Biol Ecol 215:235-245

MacLean WC, Warwick P (2003) Food energy: methods of analysis and conversion factors: report of a technical workshop, Rome, 3-6 December 2002. Food and Nutrition Paper No. 77. FAO, Rome

*Makádi M, Tomócsik A, Orosz V (2012) Digestate: a new nutrient source-review. In: Kumar S (ed) Biogas. IntechOpen, doi:10.5772/31355

* Marques B, Lillebø AI, Ricardo F, Nunes C, Coimbra MA, Calado R (2018) Adding value to ragworms (Hediste diversicolor) through the bioremediation of a super-intensive marine fish farm. Aquacult Environ Interact 10:79-88

Metcalfe L, Schmitz AA, Pelka J (1966) Rapid preparation of fatty acid esters from lipids for gas chromatographic analysis. Anal Chem 38:514-515

Nkoa R (2014) Agricultural benefits and environmental risks of soil fertilization with anaerobic digestates: a review. Agron Sustain Dev 34:473-492

Nnali KE, Oke AO (2013) The utilisation of fish and fish farm wastes in biogas production: a review. Adv Agricult Sci Eng Res 3:656-667

Øie G, Olsen Y (1997) Protein and lipid content of the rotifer Brachionus plicatilis during variable growth and feeding condition. In: Hagiwara A, Snell TW, Lubzens E, Tamaru CS (eds) Live food in aquaculture. Developments in Hydrobiology, Vol 124. Springer, Dordrecht, p 251-258 
Olive PJW (1999) Polychaete aquaculture and polychaete science: a mutual synergism. Hydrobiologia 402:175-183

Pajand ZO, Soltani M, Bahmani M, Kamali A (2017) The role of polychaete Nereis diversicolor in bioremediation of wastewater and its growth performance and fatty acid composition in an integrated culture system with Huso huso (Linnaeus, 1758). Aquacult Res 48:5271-5279

Santos A, Granada L, Baptista T, Anjos C and others (2016) Effect of three diets on the growth and fatty acid profile of the common ragworm Hediste diversicolor (OF Müller, 1776). Aquaculture 465:37-42

Spranghers T, Ottoboni M, Klootwijk C, Ovyn A and others (2017) Nutritional composition of black soldier fly (Hermetia illucens) prepupae reared on different organic waste substrates. J Sci Food Agric 97:2594-2600

Summerfelt S, Davidson JMS, May T, Good CDVM, Vinci B (2015) Emerging trends in salmonid RAS. Part 2. System enhancements. Global Aquaculture Advocate. www. aquaculturealliance.org/advocate/emerging-trends-insalmonid-ras-part-2/

Summerfelt ST, Mathisen F, Holan AB, Terjesen BF (2016) Survey of large circular and octagonal tanks operated at Norwegian commercial smolt and post-smolt sites. Aquacult Eng 74:105-110

Suthar S (2010) Recycling of agro-industrial sludge through vermitechnology. Ecol Eng 36:1028-1036

Tacon AG (1987) The nutrition and feeding of farmed fish and shrimp - a training manual. 1. The essential nutrients. FAO, Brasilia

Tacon AG, Metian M, Hasan MR (2009) Feed ingredients and fertilizers for farmed aquatic animals: sources and composition. FAO Fish Aquacult Tech Pap 540. FAO, Rome

Tocher DR (2010) Fatty acid requirements in ontogeny of marine and freshwater fish. Aquacult Res 41:717-732

Van Huis A, Van Itterbeeck J, Klunder H, Mertens E, Halloran A, Muir G, Vantomme P (2013) Edible insects: future prospects for food and feed security. FAO For Pap 171. FAO, Rome

Verreth J, Vlak J, Verdegem M (2014) Hediste diversicolor (OF Müller 1776) as a possible model to study white spot

Editorial responsibility: Adam Hughes,

Oban, UK syndrome virus infection in polychaetes. Asian Fish Sci 27:199-211

* Vijayan K, Raj VS, Balasubramanian C, Alavandi S, Sekhar VT, Santiago T (2005) Polychaete worms - a vector for white spot syndrome virus (WSSV). Dis Aquat Org 63: 107-111

*Wang H, Seekamp I, Malzahn A, Hagemann A and others (2019) Growth and nutritional composition of the polychaete Hediste diversicolor (OF Müller, 1776) cultivated on waste from land-based salmon smolt aquaculture. Aquaculture 502:232-241

* Watanabe T, Kitajima C, Fujita S (1983) Nutritional values of live organisms used in Japan for mass propagation of fish: a review. Aquaculture 34:115-143

WWiland P (2010) Biogas production: current state and perspectives. Appl Microbiol Biotechnol 85:849-860

Wilson RP (2003) Amino acids and proteins. In: Halver JE, Hardy RW (eds) Fish nutrition, $3^{\text {rd }}$ edn. Elsevier, New York, NY, p 143-179

Woulds C, Middelburg JJ, Cowie GL (2012) Alteration of organic matter during infaunal polychaete gut passage and links to sediment organic geochemistry. Part I. Amino acids. Geochim Cosmochim Acta 77:396-414

Woulds C, Middelburg JJ, Cowie GL (2014) Alteration of organic matter during infaunal polychaete gut passage and links to sediment organic geochemistry. Part II. Fatty acids and aldoses. Geochim Cosmochim Acta 136: 38-59

Xu X, Li LM, Li B, Guo WJ, Ding XL, Xu FZ (2017) Effect of fermented biogas residue on growth performance, serum biochemical parameters, and meat quality in pigs. AsianAustralas J Anim Sci 30:1464-1470

Yousefi-Garakouei M, Kamali A, Soltani M (2019) Effects of rearing density on growth, fatty acid profile and bioremediation ability of polychaete Nereis diversicolor in an integrated aquaculture system with rainbow trout (OnCorhynchus mykiss). Aquacult Res 50:725-735

Zhang C, Su H, Baeyens J, Tan T (2014) Reviewing the anaerobic digestion of food waste for biogas production. Renew Sustain Energy Rev 38:383-392

Submitted: June 7, 2019; Accepted: August 13, 2019 Proofs received from author(s): November 1, 2019 